\title{
Ultra-trace metal speciation analysis by coupling of sector-field ICP-MS to high-resolution size exclusion and reversed-phase liquid chromatography
}

Hendrik Küpper ${ }^{1,2^{*}}$, Syed Nadeem Hussain Bokhari ${ }^{1}$, Noelia Jaime-Pérez ${ }^{1}$, Lyudmila Lyubenova $^{1}$, Nermeen Ashraf ${ }^{1}$, Elisa Andresen ${ }^{1}$.

1) Biology Center of the Czech Academy of Sciences, Institute of Plant Molecular Biology, Department of Plant Biophysics and Biochemistry, Branišovská 31/1160, 37005 České Budějovice, Czech Republic

2) University of South Bohemia, Department of Experimental Plant Biology, Branišovská 31/1160, 37005 České Budějovice, Czech Republic

* Author for correspondence: Hendrik Küpper <hendrik.kuepper@ umbr.cas.cz>

Supporting information

\section{Table of contents}

Tables S1. Examples ICP-MS methods optimised for the measurements shown in this work.

Figure S1. Analysis of copper abundance in an LH1 preparation from Rhodospirillum rubrum grown on $2 \mu \mathrm{M} \mathrm{Cu}^{2+}$.

Figure S2. Measurement of a [Cd]-Chl standard. 
Tables S1. Description of contents: This supplement describes the technical parameters for adjusting the ICP-MS in order to yield optimal performance for the different tasks described here.

$\mathrm{Cu}$ method for aqueous buffer and organic matrix

Total time: $60 \mathrm{~min}$

Runs: 505

Passes: 1

Tune in aqueous buffer and with desolvating unit

Tune with methanol and acetone with spray chamber and no desolvating unit Resolution: Medium

\begin{tabular}{|c|c|c|c|}
\hline Analyte & $\begin{array}{c}\text { Mass window } \\
\text { \% }\end{array}$ & Samples/peak & $\begin{array}{c}\text { Segment duration } \\
\text { (Seconds) }\end{array}$ \\
\hline $\mathrm{Mg}^{24}$ & 140 & 20 & 1.96 \\
\hline $\mathrm{Cu}^{63}$ & 125 & 20 & 2.00 \\
\hline $\mathrm{Zn}^{66}$ & 125 & 20 & 2.00 \\
\hline
\end{tabular}

La method for aqueous buffer

Total time: $270 \mathrm{~min}$

Runs: 1795

Passes: 1

Tune in aqueous buffer

Resolution: Medium

\begin{tabular}{|c|c|c|c|}
\hline Analyte & $\begin{array}{c}\text { Mass window } \\
\%\end{array}$ & Samples/peak & $\begin{array}{c}\text { Segment duration } \\
\text { (Seconds) }\end{array}$ \\
\hline $\mathrm{Mg}^{24}$ & 125 & 20 & 0.625 \\
\hline $\mathrm{P}^{31}$ & 125 & 20 & 0.625 \\
\hline $\mathrm{S}^{32}$ & 125 & 20 & 0.625 \\
\hline $\mathrm{Ca}^{44}$ & 125 & 20 & 0.625 \\
\hline $\mathrm{Mn}^{55}$ & 125 & 20 & 0.600 \\
\hline $\mathrm{Fe}^{56}$ & 125 & 20 & 0.600 \\
\hline $\mathrm{Co}^{59}$ & 125 & 20 & 0.625 \\
\hline $\mathrm{Cu}^{63}$ & 125 & 20 & 1.000 \\
\hline $\mathrm{Zn}^{66}$ & 125 & 20 & 0.625 \\
\hline $\mathrm{La}^{139}$ & 125 & 20 & 1.750 \\
\hline
\end{tabular}

Cd method for organic matrix

Total time: $60 \mathrm{~min}$

Runs: 505

Passes: 1

Tune with methanol and acetone with spray chamber and no desolvating unit Resolution: Medium

\begin{tabular}{|c|c|c|c|}
\hline Analyte & $\begin{array}{c}\text { Mass window } \\
\%\end{array}$ & Samples/peak & $\begin{array}{c}\text { Segment duration } \\
\text { (Seconds) }\end{array}$ \\
\hline $\mathrm{Mg}^{24}$ & 140 & 20 & 1.96 \\
\hline $\mathrm{Cd}^{111}$ & 125 & 20 & 2.00 \\
\hline $\mathrm{Zn}^{66}$ & 125 & 20 & 2.00 \\
\hline
\end{tabular}


Cd method for aqueous buffer

Total time: $270 \mathrm{~min}$

Runs: 1260

Passes: 1

Tune in aqueous buffer and desolvating unit

Resolution: Medium

\begin{tabular}{|c|c|c|c|}
\hline Analyte & $\begin{array}{c}\text { Mass window } \\
\%\end{array}$ & Samples/peak & $\begin{array}{c}\text { Segment duration } \\
\text { (Seconds) }\end{array}$ \\
\hline $\mathrm{Mg}^{24}$ & 140 & 20 & 1.4000 \\
\hline $\mathrm{P}^{31}$ & 125 & 20 & 0.500 \\
\hline $\mathrm{S}^{32}$ & 125 & 20 & 2.500 \\
\hline $\mathrm{Fe}^{56}$ & 125 & 20 & 0.250 \\
\hline $\mathrm{Co}^{59}$ & 125 & 20 & 1.250 \\
\hline $\mathrm{Cu}^{63}$ & 125 & 20 & 0.250 \\
\hline $\mathrm{Zn}^{66}$ & 125 & 20 & 0.250 \\
\hline $\mathrm{Mo}^{95}$ & 125 & 20 & 1.000 \\
\hline $\mathrm{Cd}^{111}$ & 125 & 20 & 5.000 \\
\hline
\end{tabular}

Cr method for aqueous buffer

Total time: $270 \mathrm{~min}$

Runs: 1160

Passes: 1

Tune in aqueous buffer and desolvating unit

Resolution: Medium

\begin{tabular}{|c|c|c|c|}
\hline Analyte & $\begin{array}{c}\text { Mass window } \\
\text { \% }\end{array}$ & Samples/peak & $\begin{array}{c}\text { Segment duration } \\
\text { (Seconds) }\end{array}$ \\
\hline $\mathrm{Mg}^{24}$ & 140 & 20 & 1.4000 \\
\hline $\mathrm{P}^{31}$ & 125 & 20 & 0.500 \\
\hline $\mathrm{S}^{32}$ & 125 & 20 & 2.500 \\
\hline $\mathrm{Fe}^{56}$ & 125 & 20 & 0.250 \\
\hline $\mathrm{Co}^{59}$ & 125 & 20 & 1.250 \\
\hline $\mathrm{Cu}^{63}$ & 125 & 20 & 0.250 \\
\hline $\mathrm{Zn}^{66}$ & 125 & 20 & 0.250 \\
\hline $\mathrm{Mo}^{95}$ & 125 & 20 & 1.000 \\
\hline $\mathrm{Cr}^{52}$ & 125 & 20 & 5.000 \\
\hline
\end{tabular}


Figure S1. Analysis of copper abundance in an LH1 preparation from Rhodospirillum rubrum grown on $2 \mu \mathrm{M} \mathrm{Cu}^{2+}$. Acetone extract from the protein preparation of a replicate experiment. The separation was performed on a metal-free PRP-C18 2.1x250 mm column, leading to a much lower background of $\mathrm{Cu}$ than the originally used C18 column with steel housing (Fig. $8 b$ ), but otherwise confirming the $\mathrm{Cu}$ binding to the pigments (Fig. $8 \mathrm{~b}$ ).
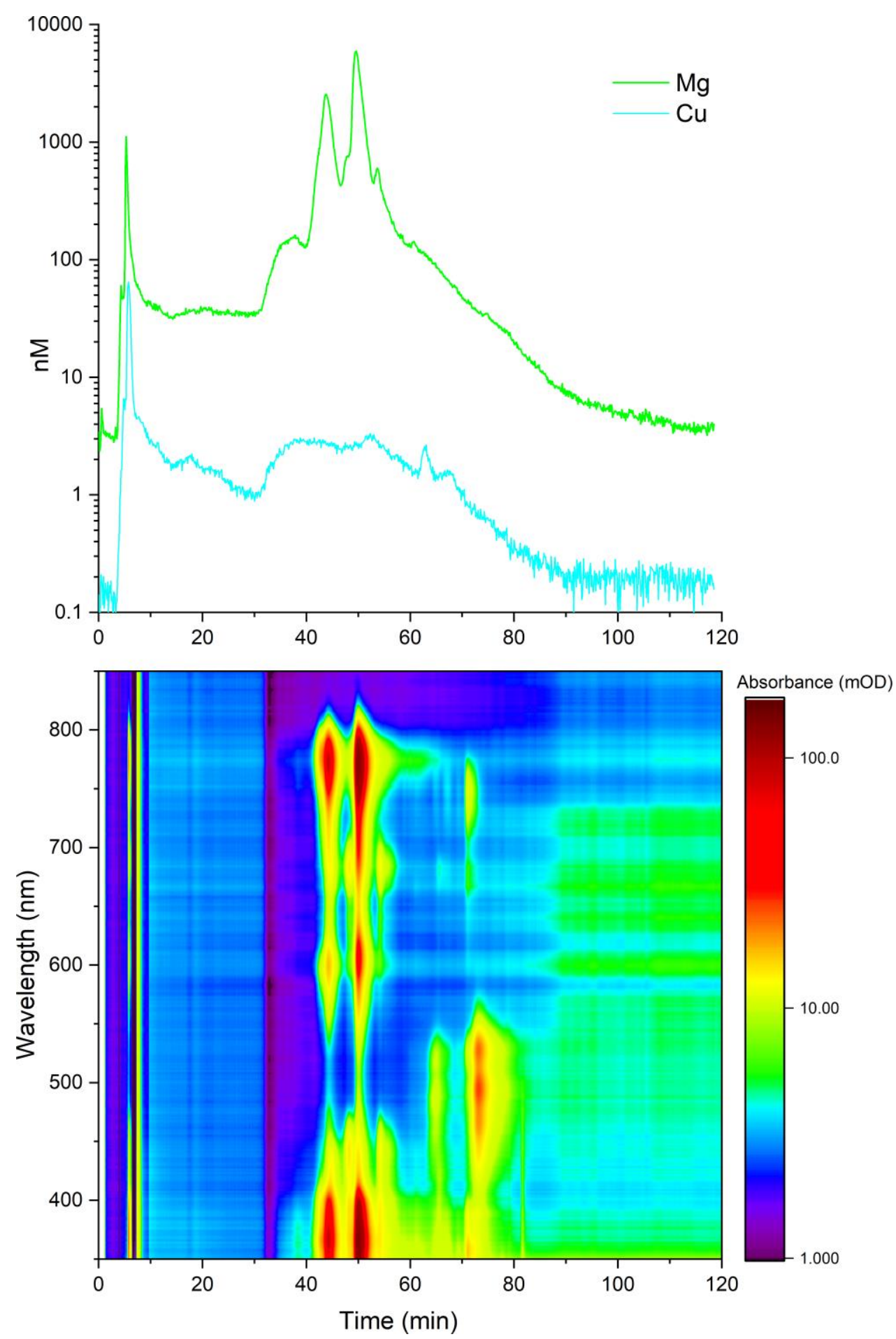
Figure S2. Description of contents: This supplement shows the HPLC-ICPMS measurement of a [Cd]-Chl standard that was prepared by Küpper et al. (2007). The separation was performed on a C18 4.6x250 mm column as described in more detail in the methods section for pigment HPLC-ICPMS
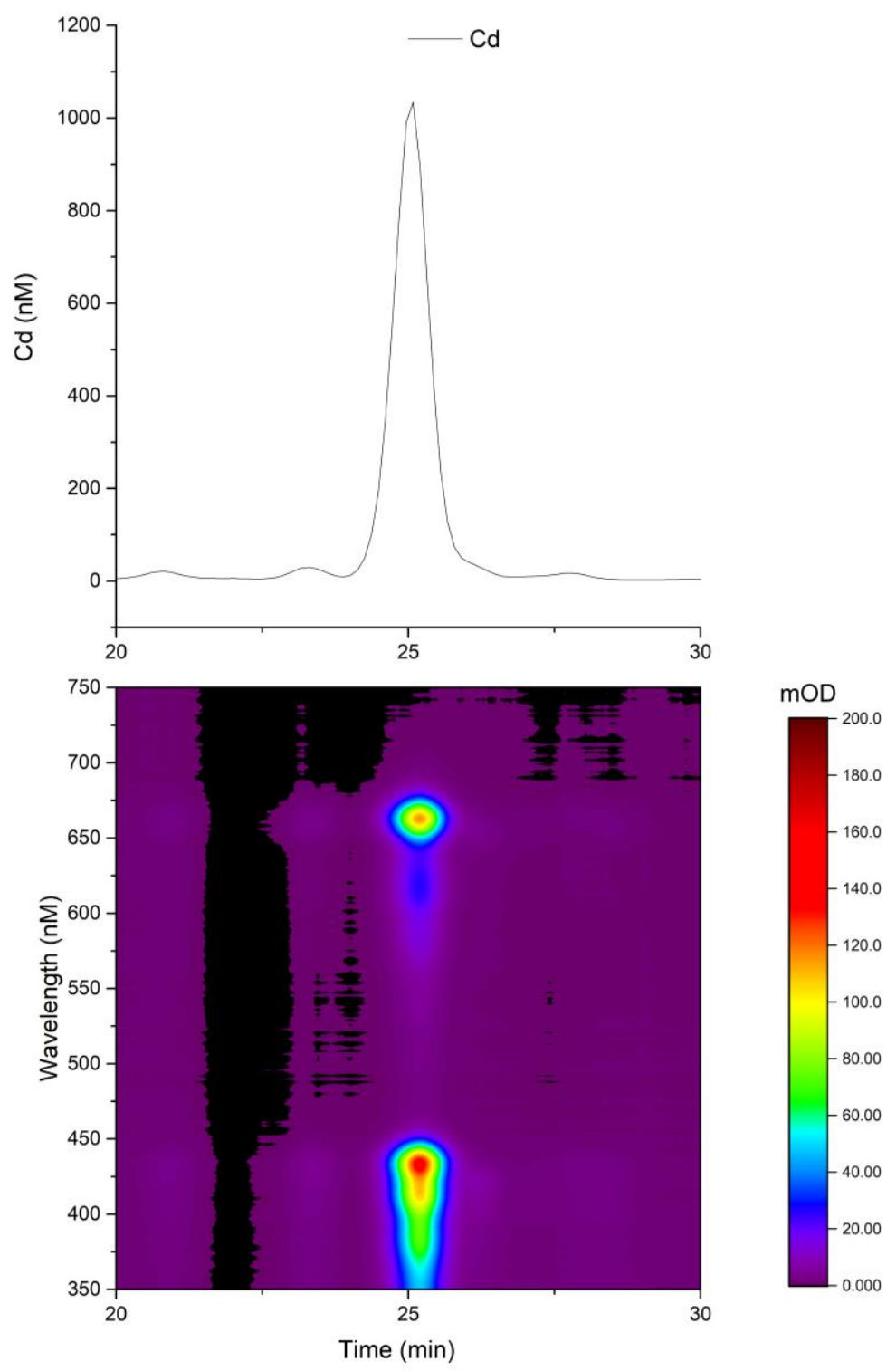